\title{
How Does a Mathematician Fit in? A Mixed-Methods Analysis of University Students' Sense of Belonging in Mathematics
}

\author{
Juulia Lahdenperä ${ }^{1}$ (D) Juuso Henrik Nieminen ${ }^{1,2}$ (ID
}

Published online: 24 July 2020

(C) The Author(s) 2020

\begin{abstract}
University mathematics has been described as a setting that has challenges in inviting everyone to be part of the mathematics community. Thus, university mathematics offers an important context for research on belonging. For this study, we utilised a mixed-methods approach to investigate the various ways mathematics students belong or do not belong to the mathematics community. Based on both quantitative and qualitative analyses, three student profiles were identified: Members of the Scientific Community, Members of the Social Community, and Non-Members. The first profile highlights students' belonging to the scientific community, the second profile emphasises belonging to the social community of students, and in the third profile students' responses reflected various ways of not belonging to the mathematics community. In addition, we elaborate on how university mathematics learning environments both promote and hinder students' sense of belonging. Overall, the study broadens the understanding of the ways of belonging in the mathematics context and provides suggestions for teaching to address the issues of exclusion that are currently present in the culture of university mathematics.
\end{abstract}

Keywords Learning environment · Mixed-methods research · Sense of belonging · Teaching practices $\cdot$ University mathematics education

\section{Introduction}

Many mathematics departments in universities around the world have historically struggled to invite everyone to be part of the mathematics community. To give one

Juulia Lahdenperä

juulia.lahdenpera@helsinki.fi

1 Department of Mathematics and Statistics, University of Helsinki, Helsinki, Finland

2 School of Educational Sciences and Psychology, University of Eastern Finland, Joensuu, Finland 
illustrative example from our university, in the history of the almost 400-year-old institution, it was only recently that the first female academic was appointed as a professor in the Department of Mathematics and Statistics. This anecdotal example represents the personal interest for the authors to conduct socio-cultural research, but it also represents larger issues of equity in university mathematics, which has been described as a context that has not been able to consider under-represented groups (Adiredja and Andrews-Larson 2017; Croft and Grove 2015). Indeed, researchers have asked, for example, why women and people of colour opt out of university mathematics (Good et al. 2012; Herzig 2004a, 2004b) and why research on university mathematics education has largely neglected disabled students (Nieminen and Pesonen 2020). Furthermore, university mathematics setting has been studied from the viewpoint of alienation (Solomon and Croft 2016). To address these issues of equity, Adiredja and Andrews-Larson (2017) draw on Gutiérrez (2013) seminal work and called for socio-political research also in the field of university mathematics education. Thus, university mathematics offers an interesting context for research on belonging. The present study investigates the ways mathematics students belong - or do not belong - to the mathematics community. In line with Good et al. (2012), we conceptualise mathematics community as a large group of people at one's higher education institution involved in the field of mathematics, including, for example, mathematics researchers, lecturers, and students. The motivation of the present study is to offer solutions for the issues of exclusion that are currently present in the culture of university mathematics, through a deeper understanding of the various ways of belonging.

How is the feeling of belonging defined? In higher educational research, sense of belonging generally refers to a feeling of connectedness, that is, a feeling that one is important to others (Rosenberg and McCullough 1981). Sense of belonging is often connected with psychological safety and, therefore, it has been conceptualised as a basic human need (Strayhorn 2019). Similar to Tovar and Simon (2010) and Osterman (2000), the present study conceptualises sense of belonging as a relational construct, implying that a person can feel low sense of belonging in one context, while at the same time feeling strong sense of belonging towards a group of people in some other context. Hagerty et al. (2002) described the absence of sense of belonging as 'sense of alienation', social isolation and marginality (see also Solomon and Croft 2016). Strayhorn (2019) sees sense of belonging as a basic human need that must be fulfilled before higher order actions can be executed. According to them, all human resources are 'preoccupied with this process and, thus, cannot be used for other purposes like focusing on the lecture, completing the lab, or acing the test [...]' (p. 161). Indeed, sense of belonging has been shown to support both academic performance (Hoffman et al. 2002; Walton and Cohen 2007, 2011) and retention in higher education (Hausmann et al. 2007; Jacoby and Garland 2004; O'Keeffe 2013; Tinto 1987).

Earlier higher education research emphasised the importance of interpersonal relationships for students' sense of belonging (Brunsting et al. 2019; Buote et al. 2007; Hoffman et al. 2002; Maunder 2018; Pascale 2018; van Gijn-Grosvenor and Huisman 2020). Sense of belonging has also been investigated in both science and university mathematics contexts. For example, Rainey et al.' (2018) study sought explanations for belonging and not belonging in STEM fields using a grounded theory approach. The study analysed 201 student interviews and identified four categories of reasons for belonging and not belonging: Interpersonal relationships, Science identity, Personal 
interest, and Competence. It seems that in the mathematics context, the central role of interpersonal relationships is emphasised, especially for under-represented student groups (Espinosa 2011; Solomon et al. 2011).

Earlier research has also shown that active learning environments in higher education offer an affordance for fostering social interaction and collaboration (Clinton and Wilson 2019; Theobald et al. 2020; Lahdenperä et al. 2019). Furthermore, both formal and informal student interaction during study at university has been connected with increased sense of belonging (Masika and Jones 2016; Meeuwisse et al. 2010; Peacock and Cowan 2019; Thomas 2012). The role of teaching practices has been shown to be central in sense of belonging in mathematics as well. For example, Solomon (2007) studied identity and belonging in first-year mathematics students and revealed that the prevailing theme was 'not belonging', and perceptions of being a potential member of the mathematics community were scarce. In line with prior research, Solomon (2007) concludes by calling for 'participatory pedagogy' that makes identity development accessible to all students (see also Solomon and Croft 2016). Elsewhere, it has been argued that mathematics support centres based on participatory approaches can foster communal co-construction of mathematics (Solomon, Croft, \& Lawson, 2010). Moreover, based on their quantitative study, Good et al. (2012) argue that teaching practices fostering the incremental theory of intelligence create opportunities for underrepresented groups to belong in the mathematics community. Therefore, it can be hypothesised that learning environments emphasising students' own activity and responsibility for learning and facilitating student collaboration support the development of sense of belonging in mathematics.

Strayhorn (2019) emphasises that even though the literature has identified sense of belonging as a major factor in students' well-being, little is known about how it varies in different subgroups of students. Widening the current conceptualisation of belonging being a continuum of 'low' and 'high' seems crucial in the context of higher education as students are adults who might have their social networks elsewhere (e.g. family). As Pascale (2018) notes, students might willingly choose not to belong if their main goal is the degree itself. Healy (2020) separates between non-belonging (loss of sense of belonging) and unbelonging (removal of sense of belonging), reminding that conscious non-belonging might even boost one's energy. However, they continues that unbelonging might have serious consequences in educational settings (Healy 2020). Therefore, it is important to understand both various ways of belonging and not belonging in the university mathematics context. Furthermore, the concept of sense of belonging is still largely missing from studies concerning solely university mathematics education. The present study addresses these research gaps by investigating mathematics student subgroups in terms of their sense of belonging. The purpose of the study is to understand the various ways in which university mathematics students belong, or do not belong, to the mathematics community. The present study is also motivated to elaborate further on the connection between teaching practices and students' sense of belonging.

\section{Aims and Research Questions}

For the present study, we used a mixed-methods approach to create student profiles differentiated by their ways of belonging to the mathematics community. The aim is to 
further understand sense of belonging as a multifaceted construct. Rather than seeing sense of belonging as a continuum of low and high 'amount' of it, the present study draws on mixed-methods approach to dig deeper into different ways students can belong to the university mathematics community. The research questions are:

1. What kinds of student clusters could be found about sense of belonging in mathematics?

2. What elements did the students in the different clusters connect with their belonging or not belonging to the mathematics community? How did these elements differ between the clusters?

The overall aim is to improve understanding of the ways of belonging and not belonging to a university mathematics community and, with this knowledge, to provide suggestions for inclusive university mathematics teaching.

\section{Methods}

A mixed-methods approach was used to answer the two research questions. In this section, the context, data collection, and data analysis are described in greater detail.

\section{Context}

The study was conducted in the mathematics departments of two research-intensive universities in Finland. The Finnish welfare state provides free tertiary education for European Union students and provides compensation for the Finnish students' living costs with a monthly grant. The university campuses do not usually include student housing. University study usually lasts for five years, with the bachelor's degree taking three years and master's degree two. However, it is common for a student to take more than five years to complete their master's degree. Students are accepted to pursue both bachelor's and master's degrees when they first enrol at university.

In upper secondary school, students study mathematics up to the concept of an integral. Therefore, the first university mathematics courses are already proof-based courses. In Finland, the Universities Act (2009) provides academic freedom for teachers in their teaching and assessment practices. Traditionally, the teaching of a university mathematics course includes six weeks of lectures (approximately five hours a week) and small group sessions (approximately two hours a week). The small group sessions consist of solving problems or going through problems students have solved prior to the session. Students often take turns to solve the problems on the blackboard. It should be noted that the two university mathematics departments are pioneers in developing their educational settings. One of the departments (Uni1) has undergone a major cultural shift towards creating a collaborative community of learners (Rämö et al. 2019). The other department (Uni2) has yet to be active in educational research, but many of the lecturers have presented their teaching innovations at international conferences. In addition, they are active members of the national community, the Network for University Mathematics Educators (NUME), the aim of which is teaching development and educational research collaboration. 


\section{Data Collection}

Mathematics students in the two mathematics departments answered an electronic questionnaire on a voluntary basis in spring 2019. The data reported in this study consisted of both quantitative and qualitative data. The data collection procedure did not require an ethical review and the research process followed the guidelines of the Finnish National Board on Research Integrity (2019).

Instrument The data was collected using an electronic questionnaire with both quantitative and qualitative items. The quantitative data were collected using the Mathematical Sense of Belonging instrument (MSoB; Good et al. 2012). First, the instrument was translated into Finnish and then back-translated into English to ensure that the meaning of the items was preserved in the process. Second, two focus groups of mathematics students were organised to discuss the translated items. Third, the authors modified the translations based on the focus group discussions. Fourth, the authors organised yet another focus group of mathematics students, after which they made the final modifications to the translations. The purpose of the process was to preserve the meaning of the original items, but at the same time to ensure that students understood the translated versions correctly.

The instrument was a 30 -item scale forming five factors. The factors were Membership (e.g. "I feel like I am part of the maths community"), Acceptance (e.g., "I feel appreciated"), Affect (e.g., "I feel comfortable"), Trust (e.g., "I trust my instructors to be committed to helping me learn"), and Desire to fade (e.g., "I wish I were invisible"). The data was collected on a five-point Likert scale $(1=$ completely disagree, $5=$ completely agree) and all items were preceded by the statement, "When I am in a maths setting...", following the data collection procedure by Good et al. (2012). At the beginning of the questionnaire, the concept of 'mathematics community' was defined as a large group of people at your institution involved in the field of mathematics, including, for example, mathematics researchers, lecturers, and other students (adapted to the Finnish context from Good et al. 2012).

The questionnaire continued with two qualitative open-ended questions: 1) What factors contribute positively to your belonging to the mathematics community? 2) What factors contribute negatively to your belonging to the mathematics community? The questions were derived from Rainey et al.' (2018) study and later, their coding scheme was used in the present study in analysing the students' responses.

Participants The students at both universities received an invitation to participate in the study via email. At Uni1, an announcement about the study was sent to the student email lists of the mathematics department and the student organisation. At Uni2, two lecturers sent an email to their students promoting the study. It is possible that the emails were received by a few hundred students, and in any case, the respondents $(N=$ 89 ) were only a small sample of the student population. This is discussed further in the section about the limitations of study. The background information of the participants $(\mathrm{N}=89)$ is shown in Table 1. Most of the participants came from Unil and speak Finnish as their first language. There was an equal number of men and women participants, and they represented all stages of university study. 


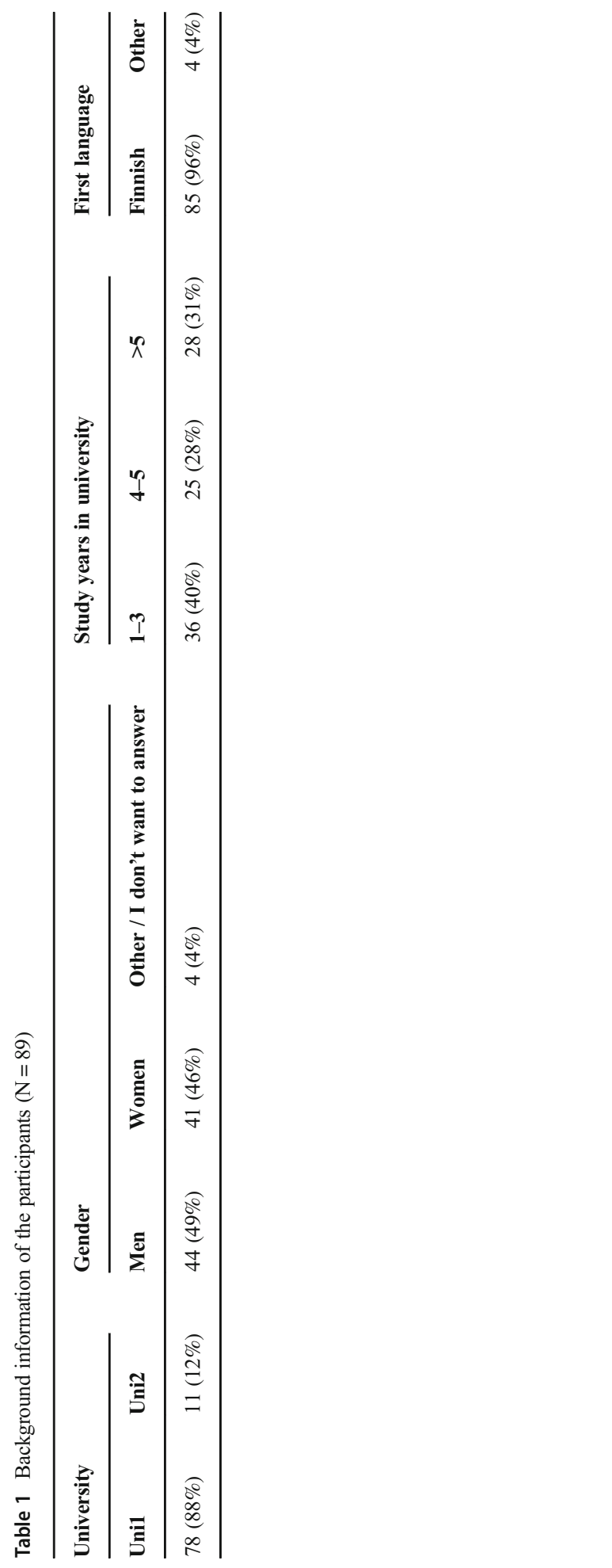




\section{Data Analysis}

The quantitative and qualitative data were analysed separately. The analysis was conducted by the authors, who both have a background in mathematics, have conducted mixed-methods research, and are familiar with the teaching and learning practices at Uni1. They also interact regularly with the lecturers in Uni2, so they were familiar with the contextual factors present in the students' responses to the open-ended questions.

Quantitative Analysis The data analysis was conducted using IBM SPSS Statistics 24 software. The instrument was used for the first time in Finnish and in a Finnish context. As the sample size was not sufficient for confirmatory factor analysis, the factor structure was analysed with exploratory factor analysis (principal axis factoring, direct oblimin rotation). The number of factors was fixed at five and they explained $57.3 \%$ of the total variance in the data. The Kaiser-Meyer-Olkin Measure of Sampling Adequacy (KMO) for the overall data set was .827 and Bartlett's test of sphericity was $p<0.001$, both supporting the performing of the factor analysis.

Based on the factor analysis, one item was deleted due to low communality, minuscule factor loading and deviant skewness and kurtosis. The deleted item was "I trust the testing materials to be unbiased" in the Trust factor. This was not surprising considering the context of Finnish higher education, in which examination culture is based on low-stakes testing and exams can be taken multiple times. Every factor was checked for internal consistency with Cronbach's Alpha which are presented in Table 2. The reliability levels are above the .7 threshold and can therefore be considered acceptable.

After the factor analysis, the participants were clustered according to their responses to the Mathematical Sense of Belonging instrument. Hierarchical clustering (Ward's method, squared Euclidean distance) was used to determine the number of clusters, and K-means clustering to identify the cluster membership. The Pearson's chi-squared test was used to investigate if the clusters differed in terms of the background variables. In addition, one-way ANOVA with Tukey's post-hoc test was used to investigate the differences between the means of the three clusters on each factor.

Qualitative Analysis The qualitative data were analysed through a theory-guided content analysis (Schreier 2012; Miles and Huberman 1994). A total of 83 students (93\%)

Table 2 The number of items and reliabilities of the five factors in the MSoB instrument

\begin{tabular}{lll}
\hline Factor & Number of items & Cronbach's Alpha \\
\hline Membership & 5 & .938 \\
Acceptance & 9 & .866 \\
Affect & 8 & .900 \\
Trust & 3 & .702 \\
Desire to fade & 4 & .784 \\
\hline
\end{tabular}


from the quantitative part of the questionnaire also provided answers to the open-ended questions. The four categories set by Rainey et al. (2018) for student perceptions of belonging or not belonging were used as a frame for the analysis and it consisted of four categories: Interpersonal relationships, Science identity, Personal interest, and Competence. Interpersonal relationships refer to a feeling of social connectedness with peers and/or faculty members (positive) or a lack of social connection and a feeling of not fitting in (negative). Science identity refers to science being part of the student's identity as a person (positive) or lacking a personal connection to the major (negative). It should be noted that the original term 'science' and not 'mathematics' was used in the category name, as the original frame was used in STEM fields including also mathematics. Personal interest refers to personal interest in the course subject or major (positive) or a lack of interest (negative). Competence refers to a feeling of understanding (positive) or not understanding (negative) major-related material.

During the analysis process, the researchers were open to new categories showing up since the framework was originally conducted in the field of STEM, not specifically in mathematics. The unit of analysis was chosen to be a coherent set of an idea (Schreier 2012). To clarify the distinction between analysis units, and between the Science identity and Personal interest categories (which were the categories most difficult to distinguish from each other in the data), an example is provided:

[My sense of belonging is supported by] my own motivation and interest towards mathematics. Also, friends from STEM fields [support my sense of belonging]. [I lack sense of belonging] because I don't feel like I'm a mathematician but more like a practitioner and a future teacher.

The student's answer includes three units of analysis, which were coded as positive for Personal interest, positive for Interpersonal relationships, and negative for Science identity, respectively. The total number of analysis units in the study was 194. Brief answers that did not fit into the four categories and included insufficient information for the building of new ones were excluded from the data (one-word responses, e.g., 'health'). The analysis was conducted with a person-oriented view in that the answers to the two questions by each student were analysed together, and each answer was interpreted against the other. The authors analysed the data independently, after which they compared their analysis sheets. Finally, all discrepancies were aligned through a discussion between the authors. The student quotes reported in this paper were originally in Finnish and have been translated into English by the authors.

\section{Results}

The participants from the present study consisted of university mathematics students who reported both quantitatively $(N=89)$ and qualitatively $(N=83)$ on their sense of belonging in mathematics. The analysis was based on the students' responses to the MSoB questionnaire (Good et al. 2012) and the two open-ended questions. The main result of the present study is the formation of three student profiles: Members of the Scientific Community (MSC; $n=41$ ), Members of the Social Community (MSoC; $N=$ 
31), and Non-Members (NM; $n=17)$. The first profile highlighted students' belonging to the scientific community, the second profile emphasised belonging to the social community, and in the third profile students' responses reflected a range of ways of not belonging to the mathematics community. Another major result of the present study was the finding of a new category - Learning environment - to supplement the framework by Rainey et al. (2018).

In the following subsections, the student profiles are described in more detail. The results are reported in four parts. The first part introduces the quantitative origin of the student profiles. The second part introduces the new Learning environment category, and the third and fourth parts report the qualitative similarities and differences between the student profiles.

\section{Quantitative Origin of the Student Profiles}

To start creating the profiles, students were clustered according to their responses to the translated Mathematical Sense of Belonging (MSoB) instrument (Good et al. 2012). First, a hierarchical cluster analysis was conducted and based on the dendrogram, a three-cluster solution was chosen as the most appropriate. K-means analysis with number of clusters fixed to three followed. After the creation of the clusters, discriminant function analysis was conducted, and it showed that $98.9 \%$ of the participants were correctly classified in their clusters. The three clusters were used as a basis for the MSC, MSoC, and NM profiles.

The means, standard deviations, and ANOVA comparisons of the profiles are presented in Table 3. The profiles were compared in terms of the background variables. Based on a Chi square test, the three profiles did not differ statistically significantly in terms of their gender $\left(\chi^{2}(4, N=89)=2.47, p=.65\right)$, study year $\left(\chi^{2}(16, \mathrm{~N}=89)=17.32\right.$, $p=.37)$ or university $\left(\chi^{2}(2, \mathrm{~N}=89)=1.07, p=.36\right)$. The profiles were then compared with a one-way ANOVA and Tukey's post hoc test to investigate whether the profiles differed statistically significantly in their scores on the five factors. The profiles showed similar trends in all five factors: the MSC profile had the highest and the NM profile had the lowest means on all factors. The mean differences were also statistically significant

Table 3 The means, standard deviations, and ANOVA comparisons of the three student profiles

\begin{tabular}{|c|c|c|c|c|c|c|c|c|c|}
\hline & \multicolumn{2}{|c|}{$\begin{array}{l}\text { MSC }{ }^{a} \text { profile } \\
(n=41)\end{array}$} & \multicolumn{2}{|c|}{$\begin{array}{l}\text { MSoC }^{b} \\
\text { profile } \\
(\mathbf{n}=\mathbf{3 1})\end{array}$} & \multicolumn{2}{|c|}{$\begin{array}{l}\mathbf{N M}^{\mathrm{c}} \text { profile } \\
(\mathrm{n}=17)\end{array}$} & \multicolumn{2}{|l|}{ ANOVA } & \multirow{2}{*}{$\begin{array}{l}\text { Post hoc } \\
\text { comparison }\end{array}$} \\
\hline & Mean & SD & Mean & SD & Mean & SD & $F(2,88)$ & $\eta 2$ & \\
\hline Membership & 4.10 & 0.59 & 3.25 & 0.57 & 1.74 & 0.48 & $105.83^{* * *}$ & 0.71 & $1>2,3^{* * *} ; 2>3^{* * *}$ \\
\hline Acceptance & 4.35 & 0.42 & 3.68 & 0.46 & 2.97 & 0.49 & $60.74 * * *$ & 0.59 & $1>2,3 * * * ; 2>3 * * *$ \\
\hline Affect & 4.05 & 0.55 & 3.01 & 0.68 & 2.94 & 0.58 & $34.38 * * *$ & 0.44 & $1>2 * * * ; 1>3 * * *$ \\
\hline Trust & 3.84 & 0.75 & 3.51 & 0.83 & 2.78 & 0.82 & $10.71 * * *$ & 0.20 & $1>3^{* * *} ; 2>3^{*}$ \\
\hline Desire to faded & 4.34 & 0.49 & 3.33 & 0.67 & 2.87 & 0.76 & $43.79 * * *$ & 0.50 & $1>2,3 * * * ; 2>3 *$ \\
\hline
\end{tabular}

${ }^{\mathrm{a}} \mathrm{MSC}=$ Members of the scientific community, ${ }^{\mathrm{b}} \mathrm{MSoC}=$ Members of the social community, ${ }^{\mathrm{c}} \mathrm{NM}=\mathrm{Non}-$ members, ${ }^{\mathrm{d}}$ Higher value means lower rate. Asterisks are used to denote the $p$-values $(*$ for $p<0.05$, and $* * *$ for $\mathrm{p}<0.001$ significance levels) 
on each factor; the general trend was that the MSC profile means were statistically significantly higher than the means of the other two profiles, and that the MSoC profile means were statistically significantly higher than the means of the NM profile. Overall, it seems that the different factors of the MSoB instrument form a one-dimensional scale.

\section{A New Category for Students' Perceptions of Belonging: Learning Environment}

A theory-guided qualitative content analysis was conducted on students' responses on the two open-ended questions (What factors contribute positively/negatively to your belonging to the mathematics community?). The analysis was based on the four categories identified by Rainey et al. (2018): Interpersonal relationships, Science identity, Personal interest, and Competence. In addition to these predetermined categories, the analysis process revealed a new category: Learning environment. This category consisted of student perceptions of elements in the teaching practices, such as lectures and small group discussions. In contrast with the other four categories, the Learning environment category included units that explicitly connected sense of belonging with the mathematics learning environments. As the students' responses also included aspects of social interaction, it is crucial to distinguish between the Learning environment and Interpersonal relationships categories; the Learning environment category does not include the social interactions per se, but instead, it referred to teaching practices that form structures for learning. For example, a student from MSC profile stated:

Lectures and small group sessions support my feeling of belonging in the mathematics community. Without these I would hardly participate in interactive learning of mathematics. (MSC profile)

The student's response implied that the teaching practices form the structures in which the interactive learning, perhaps involving peer students and teachers, takes place. The types of responses in which the students underlined that course designs and learning activities made it possible to engage in social interaction that fostered students' sense of belonging, were common. As the following two student responses show, the students usually referred to positive social encounters both with other students and with the staff members within the learning environment:

Lecturers who manage their courses (and communicate) in a clear manner have promoted my sense of belonging. (MSoC profile)

Lectures that are based on discussion. (NM profile)

The connection between Learning environments and students' sense of belonging was further elaborated by students who needed support in developing social relationships. The students reported on benefiting from learning environments that fosters or even 'forces' them to interact with others:

'Forcing' me to socialise and to create connections with the other students during the first university courses, not just in social activities outside of teaching. (NM profile) There should be more support for group work and planned situations for this at the beginning of the studies but also later on. (NM profile) 
Besides perceiving the Learning environment as a proxy to Interpersonal relationships, students reflected on the physical environment, as shown in the following quote:

The campus hallways are good places for communal mathematics studying. However, they are quite noisy and, as a consequence, it is a little hard to concentrate. It is quiet in the library, but the downside is that you are alone. (MSoC profile)

In addition to positive accounts for the Learning environments category, the students also reported on learning environments that hindered their sense of belonging. These accounts concerned teaching practices that either did not address the issues of socialisation or created negative experiences. In the following quotes, two students' responses indicate that a very negative experience within a certain learning environment can leave a long-lasting impression:

Tense atmosphere in the small groups, silence, no one is talking. (NM profile) I remember the small group sessions of this one course. That experience really got stuck in my mind. Almost every time a student who had shared their solution in front of the class started to cry, because the teacher was really not supportive at all. Even though the solution would have been correct, there was always something about the markings to nag about. These kinds of experience stick in your mind for a long time and destroy the foundation of a positive attitude. (MSoC profile)

\section{Qualitative Elaboration of the Student Profiles}

The frequency of students' responses coded into the five qualitative categories are presented in Table 4. Students who provided multiple analysis units are included in all the respective categories. For example, $70 \%$ of the students in the MSC profile gave responses that were coded into the Interpersonal relationships category. The contents of the table will be discussed in the following two subsections.

Qualitative Similarities between the Profiles Students in all three profiles largely reported that positive accounts of both Learning environment and Interpersonal relationships positively contribute to their sense of belonging in mathematics; the social aspect of studying was largely reflected in the students' responses. The responses connecting Interpersonal relationships and sense of belonging consisted of accounts of studying with friends ('friends and the supportive atmosphere', MSoC profile; 'friends who are at the same stage of their studies as I am', NM profile), about meeting other students in study-related events and organisations ('active participation in the subject association for mathematics', MSoC profile) and about warm interaction with staff:

I feel like the staff and the tutors gladly take part in open conversations which makes it easier to approach them. (MSC profile)

In terms of negative contributions to sense of belonging, students in all clusters reported on negative accounts for Interpersonal relationships and Competence. Students in all profiles reported that a lack of Interpersonal relationships contributed negatively to their sense of 
Table 4 The frequencies of different reasons for belonging and not belonging in each of the student profiles $(\mathrm{N}=83)$

\begin{tabular}{lllllr}
\hline & & $\begin{array}{l}\text { MSC } \\
\text { profile }\end{array}$ & MSoC profile & NM profile & Total \\
\hline Reasons for belonging & Interpersonal relationships & $70 \%$ & $32 \%$ & $33 \%$ & $49 \%$ \\
& Science identity & $22 \%$ & $6 \%$ & - & $12 \%$ \\
& Personal interest & $8 \%$ & $6 \%$ & $7 \%$ & $7 \%$ \\
& Competence & $8 \%$ & $3 \%$ & - & $5 \%$ \\
& Learning environments & $24 \%$ & $35 \%$ & $33 \%$ & $30 \%$ \\
Reasons for not belonging & Interpersonal relationships & $49 \%$ & $58 \%$ & $60 \%$ & $54 \%$ \\
& Science identity & $30 \%$ & $13 \%$ & $20 \%$ & $22 \%$ \\
& Personal interest & $5 \%$ & $10 \%$ & $20 \%$ & $10 \%$ \\
& Competence & $27 \%$ & $29 \%$ & $40 \%$ & $30 \%$ \\
& Learning environments & $11 \%$ & $19 \%$ & $13 \%$ & $14 \%$ \\
\hline
\end{tabular}

belonging. There were several factors related to Interpersonal relationships that hindered sense of belonging, such as personal attributes (shyness, lack of social skills, anxiousness), fear of not being accepted, lack of friends, and loneliness. For example, one student stated:

I don't have a lot of friends on the campus and I feel that I have to do all the work by myself. Sometimes it feels quite demanding. (MSoC profile)

Some students reported that when they were unable to approach the staff members (e.g., lecturers) easily, it had a negative impact on their sense of belonging. In terms of Competence, students in all profiles had doubts about whether their mathematical competence would be enough to fully become part of the mathematics community. As the following three quotes demonstrate, the students perceived mathematical competence as one of the key factors in being a member of the community:

The feeling that I'm not good enough or that others would think that I'm not good at mathematics. (MSC profile)

My level of self-criticism is high, and there's always someone who's better than me, so I can't believe in myself as much as I would want to. (MSoC profile) I feel like belonging to the mathematics community would require deeper understanding of mathematics than I currently have from the bachelor's courses that I've completed with moderate grades (GPA 3*). (NM profile; *on a scale from 1-5)

Finally, it is worth noting that the students connected Personal interest neither to positive nor negative accounts of sense of belonging in mathematics.

Qualitative Differences between the Profiles The student profiles differed qualitatively in many ways. This section describes the unique characteristics of the profiles, one profile at a time. 
The MSC profile was the only profile largely reporting both positive and negative accounts of Science identity. Many of the students in this profile explained that they had already been part of the community through working as a hired student tutor or a research assistant. Also, many students wrote that they had attended research seminars during their studies. Therefore, many students were already attached to the scientific community. For example, one student in this profile stated: 'The scientific community at the mathematics department is special'. Besides positive accounts, the students also reported on negative accounts for Science identity; students in this profile felt that they would have wanted to work in a research project but had never had the chance to do so. In addition, the students reported feeling that they were part of the student community, but not part of the broader scientific community. For example, a student in this profile stated:

Because researchers and professors are also part of the mathematics community, it is hard for me to imagine being a part of the same community as them. However, I do feel that I'm part of the same mathematics community as my peers. (MSC profile)

The students in the MSoC profile can be distinguished from the other two profiles by their extensive reports on social interaction with other students - both in terms of belonging and not belonging to the mathematics community. These accounts categorised as Interpersonal relationships were further highlighted in the students' responses, as they elaborated on their Science identity less extensively than the students in the MSC profile. The students in the MSoC profile described social interactions even within statements in the other categories. For example, the student in the following quote connected Learning environment and the academic community directly with Interpersonal relationships:

At least it helped me when I later had a chance to get to know a couple of people a bit better in courses that demanded more participation. In addition, I made some new friends from the university community in general, from a neighbouring department I mean. (MSoC profile)

The students in this profile also reported negative accounts of interpersonal relationships. Some students reported not having a lot of friends on campus; there were many reasons for this, one reason was being much older than the other students. For example, a student noted that 'the other students are closer to the ages of my children than my own'. Other students in this profile described how they were not interested in being part of the mathematics community, since they had their own communities elsewhere. For example, some students already had a job.

The students in the NM profile are unique from the other two profiles for their lack of sense of belonging. A lot of the open answers reflected on studying alone - and even a willingness to do this. This can be seen in the following student quotes:

Being unsocial and living far away from the campus. I don't like communal studying, small groups sessions, or lectures. I would rather study and work on the assignments at home by myself. (NM profile)

My habit of studying alone. I haven't got acquainted with any other mathematics students during the whole 4-5 years. (NM profile) 
I mostly study by myself, and I don't participate in social activities at the university. As an introvert, it's not easy to make casual friends with the other students on the courses. (NM profile)

Although the lack of Competence was hindering the students' sense of belonging in all three profiles, it formed a more extensive barrier for students in the NM profile to belong to the mathematics community. For example, one student described suffering from an 'inferiority complex', and another expressed their fear of 'being of less worth and less intelligent than the rest of the students'. Often, the lack of Competence was tied up with students' GPA and grades, and this reflected on the students' sense of belonging. Furthermore, students in this profile reported having fixed conceptualisations of their mathematical competence. For instance, a student described being unable to be a member of the community because of their study prior entering the university:

Too weak a level of competence, above all not enough prior knowledge. I didn't take advanced mathematics at high school and it was all badly taught, so after that you won't just 'become a member of the mathematics community'. Supposing anything else would be foolish. (NM profile)

\section{Discussion}

Higher education research has often conceptualised sense of belonging as a basic human need connected to many important factors in students' learning and studying, such as wellbeing and academic performance (Hoffman et al. 2002; Theobald et al. 2020; Walton and Cohen 2007, 2011). Given the previously-reported issues of exclusion in university mathematics context (Adiredja and Andrews-Larson 2017; Croft and Grove 2015; Good et al. 2012; Nieminen and Pesonen 2020), it is surprising how rarely the concept of sense of belonging has been directly addressed in this field. The present mixed-methods study identified three student profiles from a sample of university mathematics students based on both their responses to the Mathematical Sense of Belonging instrument (Good et al. 2012) and their answers concerning reasons for belonging or not belonging to the mathematics community (as analysed using the framework by Rainey et al. 2018).

The present study identified the three student profiles as Members of the scientific community (MSC; $n=41$ ), Members of the social community (MoSC; $n=31$ ), and Nonmembers (NM; $n=17)$. These student profiles did not differ statistically significantly in terms of any measured background variable (gender, year of study, university). In general, it is encouraging to see that most of the students belong to the first two profiles reporting, in the quantitative part of the study, relatively high sense of belonging. The cluster analysis aimed to move beyond the traditional understanding of sense of belonging as a simple continuum of 'high' and 'low' belonging, as university students might choose to belong to various communities, the university setting not automatically being the most important of them (e.g. Pascale 2018). Interestingly, the three student profiles identified in the analysis seem to implicate a division between 'low', 'medium' and 'high' sense of belonging; the student profiles acted uniformly across the five factors in the MSoB scale, implying onedimensionality of sense of belonging. Nonetheless, the cluster analysis is a novel approach 
in constructing quantitative understanding of the nuances of sense of belonging in the context of higher education.

The cluster analysis was accompanied by a qualitative content analysis of students' responses. The aim of the analysis was to understand various aspects affecting students' belonging. In addition to the four categories (Interpersonal relationships, Science identity, Personal interest, and Competence) in the earlier framework by Rainey et al. (2018), the analysis revealed a new supplementary category: Learning environment. This new category emerged in students' responses when they explicitly connected their sense of belonging with tangible teaching practices forming structures for their learning. Prior research has connected active teaching practices in higher education with increased social interaction (Clinton and Wilson 2019; Lahdenperä et al. 2019), which in turn has been repeatedly related to increased sense of belonging (see e.g. Masika and Jones 2016; Meeuwisse et al. 2010). The present study confirms a similar link in the context of university mathematics; active learning environments hold an affordance for supporting students' sense of belonging in mathematics by building structures for student interaction. The literature has reported on large-scale campus interventions (see Strayhorn 2019 for a literature review), and in the university mathematics context, on support centres (Solomon et al. 2010) and belonging from the perspective of identity (Solomon 2007; Solomon and Croft 2016). These approaches most definitely hold their place in supporting students' sense of belonging. However, as the positive accounts of the new Learning environment category supported students' sense of belonging in all three profiles, it suggests that in addition to campus-level interventions, every teacher can contribute with appropriate designs of their teaching practices. It should be noted that the two mathematics departments participating in this study have both tried to develop their teaching and to create more student-centred learning environments (see e.g. Lahdenperä et al. 2019). Therefore, the emergence of the new Learning environment category can be seen as being a result of the consistent work done to enhance students' own activity and interaction with peers and faculty members. This kind of development is supported by the Finnish context giving university teachers considerable autonomy in their teaching practices and in developing mathematics learning environments.

Unexpectedly, the students in the present study did not connect Personal interest to either positive or negative accounts for their sense of belonging. A more expected result was that the results emphasised the central role of Interpersonal relationships in sense of belonging; the most common category for all three student profiles was the (lack of) an Interpersonal relationships category, for both supporting and hindering the students' sense of belonging. This is not a new finding, as it has largely been reported in the literature (Brunsting et al. 2019; Buote et al. 2007; Hoffman et al. 2002; Maunder 2018; Pascale 2018; van Gijn-Grosvenor and Huisman 2020). However, this further elaborates on the importance of the social in learning university mathematics.

The results also suggest that besides being proxy to higher order actions (Strayhorn 2019), sense of belonging could itself form a hierarchical structure. The MSC profile - the students reporting the highest sense of belonging in the quantitative part of the study - is unique in reflecting on their Science identity. Many of these students have been working as a tutor, teaching assistant, or research assistant, and have attended research seminars that supported their belonging to the scientific community. However, they also reflected on the lack of Science identity and called for more student-faculty member collaboration and a mixing of mathematics teaching and research. In contrast, the students in the MSoC profile did not report on their Science identity or any connections with faculty members. Instead, 
they considered their (lack of) sense of belonging as (not) belonging socially to the community of students, and they see it as the result of their own actions (studying with peers, or being unable to build social networks due to clashes with work). According to Strayhorn (2019), the students in this profile are 'preoccupied' with building interpersonal relationships and cannot yet execute 'higher order' actions such as reflecting on their belonging to the scientific community. However, this can also be interpreted as students rejecting the normative scientific community and forming a social community of their own; as an implication, there exists at least two mathematics communities the students can belong to. Whether there is one mathematics community or two separate communities, namely the scientific and the social communities, the role of the social is crucial - either for serving as a proxy for belonging to the one mathematics community or providing an alternative community for students who find the scientific community non-inclusive.

Perceived competence formed a critical factor in students' responses for reasons of not belonging to the mathematics community. It was visible in all student profiles, but it was emphasised in the NM profile. This finding might not seem surprising at first; surely, belonging to an academic community requires some understanding of mathematical content. However, the students in this profile conceptualised their mathematical competence one-dimensionally, such as on a continuum from 'low' to 'high'. Rainey et al. (2018) included 'conceptual understanding' and 'communication' under the definition for Competence. Therefore, the problem for the students in the NM profile is that mathematical competence in the university setting cannot be abridged into 'low and high levels', or into grades and GPA, especially if notions such as conceptual understanding are to be addressed. This finding is in line with earlier research; Rattan and colleagues noted (Rattan et al. 2018) that in STEM fields, expanding the notion of scientific potential has a positive effect on students' sense of belonging. Therefore, this confirms that in the context of university mathematics in particular, problematising the one-dimensional notion of competence might offer a key to address issues in students' sense of belonging.

Strayhorn ends their literature review by stating that 'every student wants to belong; with our help, they will' (Strayhorn 2019, p. 172); the present study slightly disagrees with this statement by differentiating between scientific and social ways of belonging to the mathematics community. Also, the conceptualisation of sense of belonging as a relational construct acknowledges that not all students want to belong to the mathematics community due to belonging to other communities (Pascale 2018). In this study, we applied Healy's (2020) distinction between non- and unbelonging to the context of university mathematics by understanding the spectrum of different ways of not belonging to the mathematics community. Even though students would want to non-belong, educators might still have the responsibility to promote collaboration and sense of belonging, since the students' own will might not always represent what is best for them (which goes back to the core of what is meant by education - educators also want to correct unfunctional study strategies, for example). Earlier research has highlighted the affordances that online systems offer for sense of belonging, even when students would only be able to attend their courses remotely (Peacock and Cowan 2019), which offers an interesting perspective for mathematics communities. However, even more important is to promote teaching practices that prevent unbelonging and structural alienation (see Solomon 2007). The present study has highlighted that learning environments are not separate from the construct of mathematical sense of belonging but are an important part of building it. Reflecting the literature (Rattan et al. 2018; van Gijn-Grosvenor and Huisman 2020), the 
results indicate that learning environments that promote social interaction, warm classroom climate, and a broader understanding of mathematical competence, positively contribute to students' sense of belonging for different student profiles.

\section{Limitations of the Study and Future Research}

Several limitations of the study should be pointed out. First, the sample size of only 89 students should be considered when interpreting our findings, as it limited the choice of statistical measures that could be used. However, the three-cluster solution showed out consistently in each of the factors, so that the students reporting strong sense of belonging had the highest mean on all the factors in the instrument and the students reporting the weakest sense of belonging had the lowest, leaving the students reporting medium sense of belonging somewhere in the middle. This result is in line with previous research (Good et al. 2012) and to some extent, endorses the translated version of the MSoB scale. Future studies should further validate the MSoB scale in other contexts and with larger datasets. Further, the quantitative results did not differ according to age and gender, which contradicts what was reported by Good et al. (2012). It may be due to the sample size and/or the context of Finnish higher education. However, it could also be due to a biased sample, since it is possible that students with the most issues concerning sense of belonging did not participate in the study.

The quantitative data was supplemented with qualitative data aiming for a mixedmethods approach that would deepen the understanding of sense of belonging in mathematics. However, a more sophisticated mixed-methods approach, using student interviews (for example), might further elaborate on the differences in the student profiles. The recent conceptualisation of both non-belonging and unbelonging by Healy (2020) offers the field of mathematics a framework to understand the structural issues related to belonging; more extensive qualitative data might also reveal valuable information on these forms of not belonging. For example, an interesting question for future studies is whether non-belonging in the mathematics setting is about empowered free will to choose not to belong, or about alienation and unbelonging. This sets an important new viewpoint to future research on active learning environments. Earlier research has underlined that while designing university mathematics learning environments to support underrepresented student groups, it is often not enough to design for them (Nieminen and Pesonen 2020). Therefore, future studies should utilise participatory approaches that let students have their say both in designing and studying learning environments that would support sense of belonging.

Finally, the dataset was based on only one questionnaire. Future studies could apply longitudinal approaches to investigate how sense of belonging varies in different learning environments and develops during the time that students are at university. Given that previous qualitative studies have underlined the importance of teaching practices in the formation of mathematical identities and sense of belonging (Solomon and Croft 2016; Solomon 2007) and the results of the present study, there is a general need for larger and more systematic studies on the interaction between mathematics learning environments and sense of belonging.

\section{Conclusions}

As Strayhorn (2019) argues in their review, too often the research on sense of belonging takes the role of 'doing research for research's sake' (p. 3). Therefore, we 
want to offer practical teaching implications based on our findings from the present study. Our results showed that individual learning environments contributed to the overall sense of belonging in all three identified student profiles. Based on our findings we claim that every university teacher and their pedagogical practices matter. Developing student-centred learning environments that foster social interaction is one way to support students' integration into and belonging to the mathematics community. With careful design of learning environments, students' interpersonal relations, science identity, interest, and perceived competence can be allowed for, to make sure that no one is excluded from the community. As earlier research has underlined structural issues of exclusion in university mathematics setting, we argue that aligning learning environments with the pedagogical purpose of supporting belonging is especially important in university mathematics contexts. Also, based on our findings on the interplay of sense of belonging and competence, we strongly recommend that future research moves forward from a one-dimensional understanding of mathematical competence; even Rainey et al. (2018, p. 9) end up referring to 'high-achieving' students who report 'low' competence (emphasis added). Finally, the results of this study emphasise the importance of understanding the ways mathematics communities create inclusion and exclusion, and how university mathematics teachers could (and should!) eliminate those practices that clearly contribute to exclusion and alienation.

Acknowledgements The research has been partly funded by the Finnish Cultural Foundation, grant numbers 00172299 and 00182449.

The authors would like to express their gratitude to Professor Markku Hannula for his encouragement and valuable comments on the research design.

Author Contributions (CRediT) Juulia Lahdenperä: Conceptualization; Methodology; Validation; Formal analysis; Investigation; Data Curation; Writing - Original Draft; Writing - Review \& Editing; Project administration.

Juuso H. Nieminen: Conceptualization; Methodology; Validation; Formal analysis; Investigation; Data Curation; Writing - Original Draft; Writing - Review \& Editing.

Funding Information Open access funding provided by University of Helsinki including Helsinki University Central Hospital.

\section{Compliance with Ethical Standards}

Conflict of Interest On behalf of all authors, the corresponding author states that there is no conflict of interest.

Open Access This article is licensed under a Creative Commons Attribution 4.0 International License, which permits use, sharing, adaptation, distribution and reproduction in any medium or format, as long as you give appropriate credit to the original author(s) and the source, provide a link to the Creative Commons licence, and indicate if changes were made. The images or other third party material in this article are included in the article's Creative Commons licence, unless indicated otherwise in a credit line to the material. If material is not included in the article's Creative Commons licence and your intended use is not permitted by statutory regulation or exceeds the permitted use, you will need to obtain permission directly from the copyright holder. To view a copy of this licence, visit http://creativecommons.org/licenses/by/4.0/. 


\section{References}

Adiredja, A. P., \& Andrews-Larson, C. (2017). Taking the sociopolitical turn in postsecondary mathematics education research. International Journal of Research in Undergraduate Mathematics Education, 3(3), 444 465. https://doi.org/10.1007/s40753-017-0054-5.

Brunsting, N. C., Mischinski, M., Wu, W., Tevis, T., Takeuchi, R., He, Y., ... \& Coverdell, T. L. (2019). International students' social outcomes, educational status, and country of high school graduation. Journal of Studies in International Education, https://doi.org/10.1177/102831531882.

Buote, V. M., Pancer, S. M., Pratt, M. W., Adams, G., Birnie-Lefcovitch, S., Polivy, J., \& Wintre, M. G. (2007). The importance of friends: Friendship and adjustment among 1st-year university students. Journal of Adolescent Research, 22(6), 665-689. https://doi.org/10.1177/0743558407306344.

Clinton, V., \& Wilson, N. (2019). More than chalkboards: Classroom spaces and collaborative learning attitudes. Learning Environments Research, 22(3), 325-344. https://doi.org/10.1007/s10984-019-09287-w.

Croft, T., \& Grove, M. (2015). Progression within mathematics degree programmes. In M. Grove, T. Croft, J. Kyle, \& D. Lawson (Eds.), Transitions in undergraduate mathematics education (pp. 173-189). Birmingham: University of Birmingham.

Espinosa, L. (2011). Pipelines and pathways: Women of color in undergraduate STEM majors and the college experiences that contribute to persistence. Harvard Educational Review, 81(2), 209-241. https://doi. org/10.17763/haer.81.2.92315ww157656k3u.

Finnish National Board on Research Integrity (2019). The ethical principles of research with human participants and ethical review in the human sciences in Finland. Helsinki, Finland: Publications of the Finnish National Board on Research Integrity TENK 3/2019.

Good, C., Rattan, A., \& Dweck, C. S. (2012). Why do women opt out? Sense of belonging and women's representation in mathematics. Journal of Personality and Social Psychology, 102(4), 700-717. https://doi.org/10.1037/a0026659.

Gutiérrez, R. (2013). The sociopolitical turn in mathematics education. Journal for Research in Mathematics Education, 44(1), 37. https://doi.org/10.5951/jresematheduc.44.1.0037.

Hagerty, B. M., Williams, R. A., \& Oe, H. (2002). Childhood antecedents of adult sense of belonging. Journal of Clinical Psychology, 58(7), 793-801. https://doi.org/10.1002/jclp.2007.

Hausmann, L. R., Schofield, J. W., \& Woods, R. L. (2007). Sense of belonging as a predictor of intentions to persist among African American and white first-year college students. Research in Higher Education, 48(7), 803-839. https://doi.org/10.1007/s11162-007-9052-9.

Healy, M. (2020). The other side of belonging. Studies in Philosophy and Education, 39(2), 119-133. https://doi.org/10.1007/s11217-020-09701-4.

Herzig, A. (2004a). Becoming mathematicians: Women and students of color choosing and leaving doctoral mathematics. Review of Educational Research, 74(2), 171-214. https://doi.org/10.3102 /F00346543074002171.

Herzig, A. (2004b). 'Slaughtering this beautiful math': Graduate women choosing and leaving mathematics. Gender and Education, 16(3). https://doi.org/10.1080/09540250042000251506.

Hoffman, M., Richmond, J., Morrow, J., \& Salomone, K. (2002). Investigating "sense of belonging" in firstyear college students. Journal of College Student Retention: Research, Theory \& Practice, 4(3), 227-256. https://doi.org/10.2190/FDRYC-CXQ9-JQ8V-HT4V.

Jacoby, B., \& Garland, J. (2004). Strategies for enhancing commuter student success. Journal of College Student Retention: Research, Theory \& Practice, 6(1), 61-79. https://doi.org/10.2190/DRYC-CXQ9-JQ8V-HT4V.

Lahdenperä, J., Postareff, L., \& Rämö, J. (2019). Supporting quality of learning in university mathematics: A comparison of two instructional designs. International Journal of Research in Undergraduate Mathematics Education, 5(1), 75-96. https://doi.org/10.1007/s40753-018-0080-y.

Masika, R., \& Jones, J. (2016). Building student belonging and engagement: Insights into higher education students' experiences of participating and learning together. Teaching in Higher Education, 21(2), 138150. https://doi.org/10.1080/13562517.2015.1122585.

Maunder, R. E. (2018). Students' peer relationships and their contribution to university adjustment: The need to belong in the university community. Journal of Further and Higher Education, 42(6), 756-768. https://doi.org/10.1080/0309877X.2017.1311996.

Meeuwisse, M., Severiens, S. E., \& Born, M. P. (2010). Learning environment, interaction, sense of belonging and study success in ethnically diverse student groups. Research in Higher Education, 51(6), 528-545. https://doi.org/10.1007/s11162-010-9168-1.

Miles, M. B., \& Huberman, A. M. (1994). Qualitative data analysis: An expanded sourcebook. Thousand Oaks, CA: Sage. 
Nieminen, J. H., \& Pesonen, H. V. (2020). Taking universal design back to its roots: Perspectives on accessibility and identity in undergraduate mathematics. Education Sciences, 10(1). https://doi. org/10.3390/educsci10010012.

O'Keeffe, P. (2013). A sense of belonging: Improving student retention. College Student Journal, 47(4), 605-613.

Osterman, K. F. (2000). Students' need for belonging in the school community. Review of Educational Research, 70(3), 323-367. https://doi.org/10.3102/F00346543070003323.

Pascale, A. B. (2018). "Co-existing lives": Understanding and facilitating graduate student sense of belonging. Journal of Student Affairs Research and Practice, 55(4), 399-411. https://doi.org/10.1080 /19496591.2018.1474758.

Peacock, S., \& Cowan, J. (2019). Promoting sense of belonging in online learning communities of inquiry in accredited courses. Online Learning, 23(2), 67-81.

Rainey, K., Dancy, M., Mickelson, R., Stearns, E., \& Moller, S. (2018). Race and gender differences in how sense of belonging influences decision to major in STEM. International Journal of STEM Education, 5(10). https://doi.org/10.1186/s40594-018-0115-6.

Rattan, A., Savani, K., Komarraju, M., Morrison, M. M., Boggs, C., \& Ambady, N. (2018). Meta-lay theories of scientific potential drive underrepresented students' sense of belonging to science, technology, engineering, and mathematics (STEM). Journal of Personality and Social Psychology, 115(1), 54. https://doi.org/10.1037/pspi0000130.

Rosenberg, M., \& McCullough, B. C. (1981). Mattering: Inferred significance and mental health among adolescents. Research in Community \& Mental Health, 2, 163-182.

Rämö, J., Reinholz, D., Häsä, J., \& Lahdenperä, J. (2019). Extreme apprenticeship: Instructional change as a gateway to systemic improvement. Innovative Higher Education, 44(5), 351-365. https://doi.org/10.1007/s10755-0199467-1.

Schreier, M. (2012). Qualitative content analysis in practice. Thousand Oaks, CA: Sage.

Solomon, Y., \& Croft, T. (2016). Understanding undergraduate disengagement from mathematics: Addressing alienation. International Journal of Educational Research, 79, 267-276. https://doi.org/10.1016/j. ijer.2015.10.006.

Solomon, Y., Lawson, D., \& Croft, T. (2011). Dealing with 'fragile identities': Resistance and refiguring in women mathematics students. Gender and Education, 23(5), 565-583. https://doi.org/10.1080 /09540253.2010.512270.

Solomon, Y., Croft, T., \& Lawson, D. (2010). Safety in numbers: Mathematics support centres and their derivatives as social learning spaces. Studies in Higher Education, 35(4), 421-431. https://doi. org/10.1080/03075070903078712.

Solomon, Y. (2007). Not belonging? What makes a functional learner identity in undergraduate mathematics? Studies in Higher Education, 32(1), 79-96. https://doi.org/10.1080/03075070601099473.

Strayhorn, T. L. (2019). College students' sense of belonging: A key to educational success for all students. New York: Routledge.

Thomas, L. (2012). Building student engagement and belonging in higher education at a time of change. Paul Hamlyn Foundation, 100, 1-99.

Tinto, V. (1987). Leaving college: Rethinking the causes and cures of student attrition. Chicago, IL: University of Chicago Press.

Theobald, E. J., Hill, M. J., Tran, E., Agrawal, S., Arroyo, E. N., Behling, S., et al. (2020). Active learning narrows achievement gaps for underrepresented students in undergraduate science, technology, engineering, and math. Proceedings of the National Academy of Sciences, 117(12), 6476-6483. https://doi. org/10.1073/pnas.1916903117.

Tovar, E., \& Simon, M. A. (2010). Factorial structure and invariance analysis of the sense of belonging scales. Measurement and Evaluation in Counseling and Development, 43(3), 199-217. https://doi.org/10.1177 $/ 0748175610384811$.

Universities Act 558/2009. Issued 24th of July, 2009 in Helsinki, Finland.

Walton, G. M., \& Cohen, G. L. (2011). A brief social-belonging intervention improves academic and health outcomes of minority students. Science, 331(6023), 1447-1451. https://doi.org/10.1126/science.1198364.

Walton, G. M., \& Cohen, G. L. (2007). A question of belonging: Race, social fit, and achievement. Journal of Personality and Social Psychology, 92(1), 82. https://doi.org/10.1037/0022-3514.92.1.82.

van Gijn-Grosvenor, E. L., \& Huisman, P. (2020). A sense of belonging among Australian university students. Higher Education Research \& Development, 39(2), 376-389. https://doi.org/10.1080 $/ 07294360.2019 .1666256$

Publisher's Note Springer Nature remains neutral with regard to jurisdictional claims in published maps and institutional affiliations. 